\title{
Investigation of Injury Risk Factors in Adolescent Basketball Players
}

\section{Adolesan Basketbolcularda Yaralanma Risk Faktörlerinin Araştırılması}

\author{
Fatma Ünver ${ }^{1}$, Ebru Tekin ${ }^{1}$, Veysel Uludağ ${ }^{1}{ }^{1}$ Hande Şenol $^{2}$ \\ ${ }^{1}$ School of Physical Therapy and Rehabilitation, Pamukkale University, Denizli, Turkey \\ ${ }^{2}$ Department of Biostatistics, Faculty of Medicine, Pamukkale University, Denizli, Turkey
}

F. Ünver

0000-0002-3100-0818

E. Tekin

0000-0002-6984-1110

V. Uludağ (iD

0000-0002-9911-5961

H. Şenol

0000-0001-6395-7924

Geliş Tarihi/Date Received: 11.12.2019

Kabul Tarihi/Date Accepted: 18.04.2020

Yayın Tarihi/Published Online: 20.08.2020

Yazışma Adresi /

Corresponding Author:

Ebru Tekin

Pamukkale Üniversitesi, Fizik

Tedavi ve Rehabilitasyon,

Denizli, Turkey

E-mail:

ebrutekin123@gmail.com

(C2020 Türkiye Spor Hekimleri Derneği. Tüm hakları saklıdır.

\begin{abstract}
Objective: The aim of this study was to investigate the factors that increase the risk of injury in adolescent basketball players.

Materials and Methods: A total of 43 volunteer basketball players with a mean age of $12.7 \pm 1.5$ years participated in the study. The balance of the participants was evaluated by means of the Y-Balance balance test, trunk muscles endurance by static and dynamic curl-up and prone plank tests. $Q$ angles, hip external and internal rotations, abduction degrees were measured with goniometer. Functional movement screen test for injury risk factor detection was applied. Regression analysis was used to analyse the data.

Result: Participants were divided into two groups as those with functional movement screen total score of 14 or less and those with a score more than 14. Assessing the differences between the two groups, Y-balance for anterior right $(p=0.046)$, posterolateral left $(p=0.021)$ and posterolateral right $(p=0.040)$; prone plank time $(p=0.005)$ and age $(p=0.023)$ were found statistically significantly different. According to the results of the regression analysis, higher age $(p=0.028)$, increased prone plank time $(p=0.010)$, increase in the reach of the posterolateral component of the $Y$-Balance (right $p=0.049$; left $p=0.030$ ) reduce the injury risk. Effect of other factors on injury risk were not determined $(p>0.05)$.

Conclusion: Lower age in adolescent basketball players was associated with higher injury risk. High core endurance and high posterolateral extension distance, which is one of the determining parameters of dynamic balance, appeared to lower the injury risk.

Keywords: Adolescent athlete, basketball, risk of injury
\end{abstract}

öz

Amaç: Çalışmanın amacı adolesan basketbolcularda yaralanma riskini arttıran faktörlerin araştırılmasıdır.

Gereç ve Yöntemler: Çalışmaya yaş ortalaması $12.7 \pm 1.5$ yıl olan 43 gönüllü basketbol oyuncusu katıldı. Katılımcıların dengeleri Y-denge testiyle; gövde kaslarının enduransı ise statik ve dinamik curl-up ve prone plank testleriyle değerlendirildi. $Q$ açısı, kalça eksternal ve internal rotasyon, abduksiyon dereceleri gonyometre yardımıyla ölçüldü. Yaralanma risk faktörünün saptanması için fonksiyonel hareket taraması testi uygulandı. Verilerin incelenmesinde regresyon analiz yöntemi kullanıldı.

Bulgular: Katılımcılar fonksiyonel hareket taraması total skoru 14 ve altında olanlar ile üzerinde olanlar olarak iki gruba ayrıldı. İki grup arasındaki farklara bakıldığında Ydenge için anterior sağ $(p=0.046)$, posterolateral sol $(p=0.021)$ ve posterolateral sağ $(p=0.040)$; prone plank süresi $(p=0.005)$ ve yaş $(p=0.023)$ parametreleri arasında istatistiksel olarak anlamlı fark bulundu. Regresyon analizi sonucuna göre adolesan basketbol oyuncularında yaşın artması $(p=0.028)$, prone plank süresinin artması 
$(p=0.010)$, Y-dengenin posterolateral komponentinin uzanma mesafesindeki artış (sağ $p=0.049 ;$ sol $p=0.030$ ) yaralanma riskini azaltmaktadır. Diğer faktörlerin yaralanma riski üzerinde etkisi belirlenmedi $(p>0.05)$.

Sonuç: Sonuç olarak adolesan basketbol oyuncularında küçük yaşın yaralanma açısından daha yüksek risk nedeni olduğu belirlendi. "Core" enduransının yüksek olması ve dinamik dengeyi belirleyici parametrelerden posterolateral uzanım mesafesinin fazla olması yaralanma riskini düşüren faktörler olarak saptandı.

Anahtar sözcükler: Adolesan sporcu, basketbol, yaralanma riski

Available at: http://journalofsportsmedicine.org and http://dx.doi.org/10.5152/tjsm.2020.188

Cite this article as: Unver F, Tekin E, Uludag V, Senol H. Investigation of injury risk factors in adolescent basketball players. Turk J Sports Med. 2020;55(4):300-7.

\section{GíRiş}

Fiziksel aktivite ve sporun sağlık için önemli yararları bulunmaktadır. Ancak spor ve fiziksel aktivite risksiz değildir. Spor yaralanmalarının pek çoğu hayatı tehdit etmemesine rağmen kısa veya uzun vadede ağrı, güçsüzlük veya fonksiyon kaybına yol açabilir. Yaralanmalar, sporcunun spora katılıma ara vermesine neden olur (1). Sporun, doktora başvuru ve tedavi gerektiren en önemli yaralanma nedeni olduğuna dair kanitlar vardır. Adolesanların yılda \%8'inin yaralanma nedeniyle spor ve rekreasyonel faaliyetlere katılamadığı (2) ve spor yaralanmalarının ergenlerde karşılaşılan tüm yaralanmaların \%50'sini oluşturduğu tahmin edilmektedir (3). Yaralanma olasılığı veya yaralanma sonrası tam rehabilitasyonun gerçekleşmemesi, sağlığa yararlı olacak spor ve eğlence etkinliklerine katılma oranını etkilemektedir (4).

Yaralanmalara farklı risk faktörleri neden olmaktadır. Farklı sporlarda firlatma hareketleri ortak aşamalarla gerçekleşir. Her firlatma hareketi alt ekstremiteden üst ekstremiteye doğru bir enerji transferi içerir. Kinetik enerjinin $\% 50$ 'sinden fazlası bu atış hareketi sırasında bacaklar ve gövde yoluyla üst ekstremiteye aktarılır (5-7). Bu nedenle bu kinetik zincirdeki eksiklikler yaralanma risk faktörüdür. Sınırlı sayıda kanıt (8-12) olsa da, "core" stabilizasyon egzersizlerinin özellikle alt ekstremite için yaralanma önleme programlarına eklenmesinin yaralanma oranlarını azalttığı gösterilmiştir.

Așırı kullanım yaralanmalarının, ergenlik sırasında daha sık ortaya çıkma ihtimali olduğu ileri sürülmektedir. Hızlı büyüme evresinde kemik gelişimi tamamlanmamış sporcularda apofizler ve eklem yüzeyleri; gerilme, kayma ve basma kuvvetlerine karşı gelişimi tamamlanmış kemikten daha az dirençlidir. Bu duruma yaşla kemik mineral yoğunluğunda düşüş de neden olabilir. Yaralanmaya katkısı olabilecek diğer faktörler; büyüme, göreceli olarak yağsız doku kütlesi eksikliği, eklem hipermobilitesinde artış ve kas kuvvetindeki dengesizlikler olarak sıralanabilir (13). "Overuse" yaralanmalarının nedeninin belirlenmesi konusunda net bir fikir birliği yoktur. Buna rağmen, genel olarak kas iskelet sistemindeki tekrarlayan submaksimal yüklenmeler ve dinlenme süresinin dokulardaki adaptasyonun gerçekleşmesi için yeterli olmadığ geldiği bilinmektedir $(14,15)$. Literatürdeki yaralanma riski ile ilgili çalışmalar incelendiğinde (16-21) esneklik, core enduransı, Y-denge testi (YBT), fonksiyonel hareket taraması (FMS) ve Q açısını değerlendiren sınırlı sayıda çalışma görülmektedir. Bununla birlikte, adolesan basketbol oyuncularında YBT, core enduransı, gövde fleksiyon enduransı ve FMS yaralanma ilişkisine bakan bir çalışma göze çarpmamaktadır.

YBT güç, esneklik, propriyoseption gerektiren dinamik bir testtir ve fiziksel performansı değerlendirmek, kronik ayak bileği instabilitesini tanımlamak ve alt ekstremite yaralanması için daha büyük risk altındaki sporcuları tanımlamak için kullanılmaktadır (22). YBT ile yaralanma riski yüksek bireyler arasında ilişki kuran çalışmalarda; ekstremiteler arası uzanma farkları asimetri olarak nitelendirilmiş ve asimetrileri olan bireyler yaralanma riski yüksek grup olarak görülmüştür. Hatta, $4 \mathrm{~cm}$ 'den daha fazla anterior asimetri, hangi bireylerin yaralanma riskinin yüksek olduğunu tahmin etmek için önerilmiştir (18).

FMS insan hareketine temel oluşturan yedi hareket paterninin belirli kriterlere göre puanlamasını esas alan bir sistemdir. Değerlendirme 
sistemi içerisindeki testler ile fonksiyonel hareket paternlerinin, mobilite ve stabilitenin puanlanması amaçlanır. $\mathrm{Bu}$ test yaralanma riski hakkında fikir vermektedir. Puanı $\leq 14$ olan sporcuların $>14$ puan alanlara göre yaralanma riskinin dört kat daha fazla olduğu görülmüștür (23). Bu çalışmayı referans alan çalışmamızda FMS skorunun $\leq 14$ olmasina etki eden, yani yaralanma riskini arttıran etmenler üzerinde duruldu. Bu özelliğiyle literatürde benzeri olmadığı düşünülmektedir.

Yaralanma risk faktörlerini saptamaya yönelik ilgi son zamanlarda artmakla birlikte, özellikle gelişim çağındaki adolesan sporcuların yaralanmaya açık oldukları belirtilmiştir (13). Adolesan basketbol oyuncularında FMS, YBT ve core enduransı ve gövde fleksiyon enduransının yaralanma riskine etkisi yönünde yapılmış bir çalışma gözlenmemektedir. Yaralanma risk faktörlerinin saptanması, yaralanmalardan korunma amaçlı çalışmalara yön vermesi nedeniyle önemlidir. Bizim çalışmamızda bu nedenlerle adolesan basketbol oyuncularında yaralanma risk faktörlerini araştırmak amaçlanmaktadır.

\section{GEREÇ ve YÖNTEM}

Çalışma için 24.10.2019 tarih ve 60116787020/75828 numaralı girişimsel olmayan klinik araştırmalar etik kurul kararıyla izin alındı. Çalışmamıza Denizli'de amatör bir spor kulübündeki, yaş aralığı 10-16 yıl arasında olan 9'u kız 34'ü erkek olmak üzere 43 gönüllü basketbol oyuncusu katıldı. Katılımcıların yaş, boy, kilo, eğitim bilgileri ve antrenman yaşları kaydedildi. Çocuklarda güvenilirlik çalışması yapılmış olan testlerle (24-26), gövde fleksiyon ve core kaslarının enduransı değerlendirildi. Çalışmaya katılan bireylere aşağıdaki testler uygulandı.

\section{Gövde fleksiyon ve core kasları endurans testleri}

Dinamik curl up testi: Katılımcı dizler bükülü sırt üstü yatış pozisyonunda iken kollarını uzattığında topuğu ile en uzun parmağı arasında 4.5 inçlik mesafede bulunması sağlandı. Parmakları topuk hizasını geçmeyecek şekilde öne doğru uzanması istendi. Test sonlandırılmadan önce sadece iki hataya izin verildi. Analiz için toplam tekrar sayısı kullanıldı.
Statik curl up testi: Katılımcl dinamik curl up testindeki pozisyona getirildi. Öne doğru yerden yükselmesi istendi. Aynı 4.5 inçlik mesafenin dışına çıkmaması yani ellerinin topuğunu geçmemesi istendi. Üçüncü hatasında test durdurulup süre kaydedildi.

Prone plank testi: Yüzükoyun uzanmada sadece dirsekler ve ayak parmaklarının mat ile temas etmesine izin verildi. Katılımcının gövdelerini yerden yükseltmeleri istendi. Pozisyon bozulmalarını üç saniyeden fazla sürede düzeltmemeleri halinde test sonlandırıldı. Analiz için uygun pozisyonda kalınan toplam süre kullanıldı.

\section{Normal eklem hareket açıklığı değerlendir- me}

Kalça internal rotasyonu, eksternal rotasyonu ve abduksiyonu normal eklem aralığı gonyometrik ölçüm yapılarak aktif olarak değerlendirildi.

\section{$\mathbf{Q}$ açısı değerlendirmesi}

$\mathrm{Q}$ açısı $1^{\circ}$ aralıklı bir gonyometre ile (Aesculap) ölçüldü. Ölçümler diz eklemi tam ekstansiyonda ve $90^{\circ}$ fleksiyonda iken her iki ekstremitede ikişer kez yapıldı $(27,28)$. Ölçümlerin ortalaması kaydedildi.

\section{Fonksiyonel hareket taraması (FMS)}

FMS insan hareketine temel oluşturan yedi hareket paterninin belirli kriterlere göre puanlanmasını esas alan bir sistemdir. Değerlendirme sistemi içerisindeki testler ile fonksiyonel hareket paternlerinin, mobilitenin ve stabilitenin puanlanması amaçlanır. $\mathrm{Bu}$ üç ana kriterin değerlendirmesi motor kontrolün kompleks yapısı hakkında bilgi verir. Sistemdeki üç test fonksiyonel hareketi, iki test esnekliği ve iki test stabiliteyi değerlendirmek için kullanılır. Uygulanan testteki hareketler sırasıyla, derin çökme, engel adımı, ileriye düz çökme, omuz hareketliliği, aktif düz bacak kaldırma, şınav, gövde rotasyon dengesidir.

Testte önce kendi içinde tek taraflı değerlendirilen hareketler (derin çökme, şınav testi) ölçüldü. İki taraflı ölçülen testlerde ise (engel adımı, ileri düz çökme, omuz hareketliliği, aktif düz bacak kaldırma ve gövde rotasyon dengesi); sağ ve sol olmak üzere ayrı ayrı puanlama yapıldı. Puanlamada katılımcıların vücutlarının her iki yö- 
nünden aldığı skorlar dikkate alındı. Hareketten aldığg en düşük puan testin sonucu olarak kabul edildi. Her bir hareket paterni 0-3 arasında puanlandı ve yedi hareket paterninin puanı toplanarak toplam bir puan elde edildi. Her bir alt birimin puanı kendi içerisinde toplanarak da değerlendirilebilir. Yüksek puan hareketin iyi olduğunu gösterir $(29,30)$. Bununla birlikte $\leq 14$ puan alan (maksimum skor 21) sporcuların $>14$ puan alanlara göre yaralanma riskinin dört kat daha fazla olduğu belirtilmektedir (23).

\section{Denge değerlendirmesi}

Y-balance testi (YBT): YBT'de katılımcı anterior, posteromedial ve posterolateral olmak üzere üç pozisyonda ekstremitenin biri platformda sabitken diğer ekstremite ile bu yönlere uzanmaya çalışır. Teste başlamadan önce sağ ve sol ekstremite uzunluğu mezura yardımıyla ölçülüp kaydedildi. Spesifik test sırası sağ anterior, sol anterior, sağ posteromedial, sol posteromedial, sağ posterolateral ve sol posterolateral olarak uygulandı. Katılımcı eğer dengeli bir şekilde başlangıç pozisyonuna dönemediyse, YBT kutusuna ağırlığını vererek hareket ettirmişse veya destek ayağını platformdan kaldırmışsa deneme geçersiz kabul edildi ve test tekrarlandı. Her ekstremite için uzanma mesafesi üç kez ölçüldü, maksimum uzanma değerleri kullanılarak hesaplama yapıldı. Bu verilerle kompozit uzanma mesafesi, ekstremitenin üç yöndeki maksimum uzanım mesafelerinin toplanıp ekstremite uzunluğunun üç katına bölünmesiyle hesaplandı (31).

\section{İstatistik}

Veriler SPSS 25.0 (IBM SPSS 25 Software, IBM Corp, Armonk, NY, USA) paket programiyla ana- liz edildi. Sürekli değişkenler ortalama \pm standart sapma ve kategorik değişkenler sayı ve yüzde olarak ifade edildi. Verilerin normal dağılıma uygunluğu Shapiro-Wilk testi ile incelendi. Parametrik test varsayımları sağlandığında bağımsız grup farklılıklarının karşılaştırılmasında iki ortalama arasındaki farkın anlamlılık testi kullanıldı. Parametrik test varsayımları sağlanmadığında ise bağımsız grup farklılıklarının karşılaştırılmasında MannWhitney U testi kullanıldı. Bağımlı değişken üzerinde etkisi olan faktörlerin belirlenmesinde ise lojistik regresyon analizi kullanıldı. Tüm analizlerde $\mathrm{p}<0.05$ düzeyi istatistiksel olarak anlamlı kabul edildi.

\section{BULGULAR}

Yaşları 10-16 arasındaki (ortalama $12.7 \pm 1.5$ yll) 43 adolesan basketbol oyuncusunun katıldığı çalışmada FMS total skoru $\leq 14$ olan 22 (\%51); skoru >14 olan 21 birey (\%49) vardı. Adolesan sporcuların FMS ortalaması $14.1 \pm 2.5$ bulundu. Katılımcıların \%21'i kadın, \%79'u erkekti. Katılımcıların fiziksel tanımlayıcı verileri Tablo 1'de, test sonuçları ise Tablo 2'de gösterilmektedir.

Katılımclar FMS total skorlarına göre belirtilen aralıklarda iki gruba ayrıldı. Gruplar arasındaki farklara bakıldığında YBT anterior sağ $(p=0.046)$, YBT posterolateral sol $(p=0.021)$, YBT posterolateral sağ $(\mathrm{p}=0.040)$, prone plank test $(\mathrm{p}=0.005)$ ve yaş $(\mathrm{p}=0.023)$ için istatistiksel olarak anlamlı fark bulundu. Diğer değerler için istatistiksel olarak anlamlı bir fark saptanmadı ( $p>0.05)$. İki grup arasındaki farklar Tablo 1 ve 2 'de gösterilmektedir.

Tablo 1. Fiziksel tanımlayıcı özellikler

\begin{tabular}{|c|c|c|c|}
\hline Parametre & $\begin{array}{c}\text { FMS skoru } \leq \mathbf{1 4} \\
(\mathrm{n}=22)\end{array}$ & $\begin{array}{c}\text { FMS skoru >14 } \\
(n=21)\end{array}$ & $\mathbf{p}$ \\
\hline Yaş (yıl) & $12.2 \pm 1.2$ & $13.3 \pm 1.6$ & $0.023^{*}$ \\
\hline Boy $(\mathrm{cm})$ & $156.3 \pm 7.9$ & $161.2 \pm 11.6$ & $>0.05$ \\
\hline Vücut ağırlığı (kg) & $48.9 \pm 12.3$ & $47.3 \pm 8.3$ & $>0.05$ \\
\hline BKİ $\left(\mathrm{kg} / \mathrm{m}^{2}\right)$ & $19.8 \pm 3.9$ & $18.2 \pm 2.5$ & $>0.05$ \\
\hline
\end{tabular}


FMS total skoruna göre yaralanma riski yüksek olan ve olmayan bireylere farklı değișkenler etki etmektedir. Regresyon analiz sonuçlarına göre (Tablo 3) katılımcılarda yaşı artması $(p=0.028)$, prone plank duruş süresinin artması $(\mathrm{p}=0.010)$, YBT testinin posterolateral bileşkesinin uzanma mesafesindeki artış (sağ $\mathrm{p}=0.049$; sol $\mathrm{p}=0.030$ ) yaralanma riskini düşürücü etkidedir. Diğer faktörlerin yaralanma riski üzerinde etkisi gözlenmedi $(\mathrm{p}>0.05)$.

Tablo 2. Katılımcıların test sonuçları

\begin{tabular}{|c|c|c|c|}
\hline Parametre & FMS skoru $\leq 14(\mathrm{n}=22)$ & FMS skoru >14 $(\mathrm{n}=21)$ & $\mathbf{p}$ \\
\hline FMS total (puan) & $12.1 \pm 1.6$ & $16.2 \pm 1.0$ & $>0.05$ \\
\hline YBT anterior (sağ) & $60.4 \pm 9.2$ & $64.2 \pm 7.30$ & $0.046^{*}$ \\
\hline YBT anterior (sol) & $59.4 \pm 9.3$ & $62.4 \pm 7.5$ & $>0.05$ \\
\hline YBT posteriomedial (sağ) & $83.8 \pm 12.3$ & $87.3 \pm 22.1$ & $>0.05$ \\
\hline YBT posteriomedial (sol) & $85.9 \pm 12.5$ & $92.3 \pm 11.6$ & $>0.05$ \\
\hline YBT posteriolateral (sağ) & $86.4 \pm 9.5$ & $93.0 \pm 11.1$ & $0.040^{*}$ \\
\hline YBT posteriolateral (sol) & $85.2 \pm 8.6$ & $92.1 \pm 10.2$ & $0.021^{*}$ \\
\hline $\mathbf{Q}$ açısı (sağ) $\left(^{\circ}\right)$ & $15.0 \pm 3.8$ & $16.0 \pm 2.8$ & $>0.05$ \\
\hline $\mathbf{Q}$ açısı (sol) $\left(^{\circ}\right)$ & $15.3 \pm 3.3$ & $15.8 \pm 3.4$ & $>0.05$ \\
\hline Prone plank (s) & $22.5 \pm 12.0$ & $43.9 \pm 29.3$ & $0.005^{*}$ \\
\hline Statik curl up (s) & $41.3 \pm 31.5$ & $46.0 \pm 27.3$ & $>0.05$ \\
\hline Dinamik curl up (s) & $20.6 \pm 7.2$ & $26.3 \pm 13.7$ & $>0.05$ \\
\hline Kalça abduksiyon $($ sağ $)\left({ }^{\circ}\right)$ & $54.6 \pm 7.1$ & $56.4 \pm 10.3$ & $>0.05$ \\
\hline Kalça abduksiyon (sol) $\left(^{\circ}\right)$ & $55.7 \pm 8.6$ & $54.6 \pm 9.6$ & $>0.05$ \\
\hline Kalça eksternal rotasyon (sağ) $\left(^{\circ}\right)$ & $39.5 \pm 6.9$ & $37.3 \pm 4.0$ & $>0.05$ \\
\hline Kalça eksternal rotasyon $(\mathrm{sol})\left({ }^{\circ}\right)$ & $39.6 \pm 5.2$ & $38.2 \pm 5.7$ & $>0.05$ \\
\hline Kalça internal rotasyon $(\mathrm{sağ})\left(^{\circ}\right)$ & $39.6 \pm 6.1$ & $44.0 \pm 10.9$ & $>0.05$ \\
\hline Kalça internal rotasyon $(\mathrm{sol})\left(^{\circ}\right)$ & $39.4 \pm 5.9$ & $42.7 \pm 9.8$ & $>0.05$ \\
\hline YBT anterior asimetri $(\mathrm{cm})$ & $3.64 \pm 2.92$ & $4.00 \pm 3.03$ & $>0.05$ \\
\hline YBT posteriomedial asimetri $(\mathrm{cm})$ & $3.82 \pm 3.43$ & $4.14 \pm 3.15$ & $>0.05$ \\
\hline YBT posteriolateral asimetri $(\mathrm{cm})$ & $3.91 \pm 2.29$ & $3.14 \pm 2.17$ & $>0.05$ \\
\hline
\end{tabular}

Değerler aritmetik ortalama \pm standart sapma olarak verilmektedir. FMS: fonksiyonel hareket taramasl; YBT: Y-balance testi; *: $p<0.05$

Tablo 3. Regresyon analizi sonuçları

\begin{tabular}{llll}
\hline Parametre & $\mathbf{p}$ & OR & \%95 GA alt-üst sınırlar \\
\hline Yaş (10-16) & $0.028^{*}$ & 0.577 & $0.353-0.944$ \\
Prone plank duruş süresi & $0.010^{*}$ & 0.940 & $0.896-0.985$ \\
Y balance posterolateral (sağ) & $0.049^{*}$ & 0.937 & $0.879-1.000$ \\
Y balance posterolateral (sol) & $0.030^{*}$ & 0.924 & $0.860-0.992$ \\
\hline OR: odds ratio; GA: güven aralı̆ğ, *: $p<0.05$ &
\end{tabular}

\section{TARTIŞMA}

Adolesan basketbolcularda yaralanma riskine etki eden faktörleri araștırmak amacıyla FMS skoru $\leq 14$ ve altı yaralanma riski yüksek, $>14$ yaralanma riski düşük olmak üzere iki gruba ayrildı. YBT anterior, YBT posterolateral sağ, YBT posterolateral sol, prone plank süresi ve yaş değerleri istatistiksel olarak anlamlı farklı 
bulunurken, regresyon analizi sonucunda ise yaralanma riski düşük olan grupta yaşın ve diğer parametrelerin yüksek oldukları belirlendi.

Literatürde FMS skorunun yaralanma riski üzerine etkisi referans alınarak benzer nitelikte çalışma görülmemesine karşın; FMS, YBT, core enduransı, gövde fleksiyon enduransı, $Q$ açısı veya esneklik parametrelerinin yaralanma riski ile ilişkili çalışmalar bulunmaktadır. Sara ve ark.'nın voleybol oyuncularında dinamik denge, core enduransı ve FMS arasındaki ilişkiye baktıkları çalışmada (19) kadınlarda (n=15) YBT ve FMS skoru arasında istatistiksel olarak anlamlı ilişki saptanırken, erkeklerde $(n=15)$ saptanmamıștır. Erkeklerde gövde fleksiyon enduransı ve FMS arasında istatistiksel olarak anlamlı ilişki bulunmuşken, kadınlarda bulunmamıştır. Bizim çalıșmamızda ise YBT ve core enduransinın yaralanma riski nedeniyken, gövde fleksiyon enduransının yaralanma riski üzerine etkisi belirlenmedi. Bu fark adolesan sporcularda kas kuvvet gelişiminin henüz tamamlanmamasından kaynaklanabilir (14).

Nicole ve ark. (18) ise çoğunluğu futbolculardan oluşan sporcularda yaralanma öyküsünü, FMS ve YBT test puanlarını cinsiyete göre karşılaştırmışlar ve istatistiksel olarak anlamlı farklılıklar belirlemişlerdir. Çalışmamızda sayı yeterli olmadığı için cinsiyet karşılaştırması yapamamamız bir sınırlılıktır. Kelleher ve ark. (17) ise postüral kontrolün içinde bulunması nedeniyle YBT'nin FMS için bir alt bileșen olup olmayacağını incelemişlerdir. YBT anterior komponenti ile FMS arasında istatistiksel olarak anlamlı bir ilişki saptanmazken posterior komponentler arasında zayıf korrelasyonlar gözlenmiş; dinamik postüral kontrolün FMS'nin bir alt bileşeni olabileceği belirtilmiştir. Çalışmamızda ise YBT anterior komponenti için FMS $\leq 14$ ve FMS $>14$ olan gruplar arasinda istatistiksel olarak anlamlı farklılık belirlenirken regresyon analizi sonucu bunu desteklemedi. YBT posterolateral sağ ve sol için yaralanma riski yüksek ve düşük olan gruplar arasında istatistiksel olarak anlamlı farklılık vardı ve regresyon analizi bu sonucu destekledi. Bu durum $\mathrm{Y}$ denge testinin posterolateral komponentinin risk faktörü olabileceğine işaret edebilir.
YBT ile yaralanma riski arasında ilişki kuran çalışmalarda (18) asimetrileri bulunan bireylerin riski yüksekti. Ayrıca $4 \mathrm{~cm}$ 'den fazla anterior asimetrisi, basketbol oyuncuları hangi bireylerin alt ekstremite yaralanma riski ile karşı karşıya olduğunu tahmin etmek için önerilmiştir. Adolesan basketbolculardaki çalışmamızda YBT asimetrileri risk faktörü olarak saptanmadı. Grant ve ark. (20) yaralanma riski hakkında görüş bildirmek için Y denge testi komponentleri ile kalça abduksiyon, internal ve eksternal rotasyon ilişkisine bakmışlar istatistiksel olarak anlamlı bir ilişki bulmamışlardır. Biz de kalça abduksiyon, kalça internal ve eksternal rotasyon değerlerinin FMS sonuçlarına göre yaralanma riskine etkisi açısından benzer şekilde istatistiksel olarak anlamlı bir sonuç belirlemedik.

Yaralanma risk faktörü olabilecek bir diğer parametre ise biyomekanik fonksiyonun ve alt bacağın normal hizalanmasının önemli bir göstergesi olan $Q$ açısıdır. Alt ekstremitenin fonksiyonel kabiliyeti hakkında önemli bilgi sağlar (21). Pefanis ve ark. (21) basketbol, futbol ve voleybol branşlarında 45 bireyde yaptıkları çalışmalarında radyografi ile $Q$ açısı ölçümü yapmışlar ve alt ekstremite yaralanmaları (ayak bileği burkulmaları) ile istatistiksel olarak anlamlı bir ilişki bulmamışlardır. Bizim çalışmamızda da benzer şekilde adolesan basketbol oyuncularında $\mathrm{Q}$ açısı yaralanma risk faktörü olarak öne çıkmadı.

Perry ve ark. (32) ortalama 50 yașındaki bireylerde FMS normative değerlerine bakmışlar ortalama skor olarak $14.1 \pm 2.9$ bulmuşlar ve beden kütle indeksi, yaş ve FMS skoru arasında negatif bir ilişki saptamışlardır. Yaşın artması yetişkin bireylerde yaralanma riskini arttırmıştır. Adolesan sporcular için FMS ortalama 14.1 \pm 2.5 skoru benzer olmasına karşın, yaşın küçük olmasının, yaralanma riskini arttırıcı bir etkisinin olduğu belirlendi. Sonuç olarak yaşın yaralanma risk faktörü olarak etkili olduğu görülmektedir. Ayrıca literatürde $(33,34)$ FMS total skorlarının çocukların gelişim sürecinden etkilendiği yönünde sonuçlar vardır. Bu durum çalışmamızda küçük yaşın yaralanma risk faktörü olma bulgusunu desteklemektedir. 
Core kasları enduransının yaralanma önleme ve performans geliştirme açısından önemi son on yılda minimal destekleyici kanıtlarla popüler hale geldi. Sinırlı sayıda kanıt olmasına rağmen (7-11) core kasları endurans egzersizlerinin özellikle alt ekstremite için yaralanma önleme programlarma dahil edilmesinin yaralanma oranlarını azalttığı belirtilmektedir (7). Walden ve ark. (11) 12-17 yaş arası 4564 İsveç'li futbolcudaki çalışmalarında 121 kulüp oyuncusuna (kontrol grubu 109 kulüp) bir sezon boyunca 15 dk'lık nöromüsküler ısınma programı (core kaslarının dengeyi hedef alan enduransı) uygulatmışlar; sonuç olarak bu grupta ön çapraz bağ yaralanması oranını \%64 daha düşük bulmuşlardır. Kiani ve ark. (8) 13-19 yaş arasındaki kadın futbolcuda ( $n=1506)$ diz yaralanmaları sayısını azaltmaya yönelik olarak özel olarak tasarlanan bir fiziksel egzersiz programını, yaralanma riski bilincini arttırmak için sporcuların, ebeveynlerin ve antrenörlerin eğitimi ile birleștirmişlerdir. Eğitim programı motor becerileri, vücut kontrolünü ve kas aktivasyonunu geliştirmeyi amaçlamış; sonuçta diz yaralanması insidansı \%77 düşmüștür. Bizim çalışmamız da bu çalışmaları destekler nitelikte core enduransının FMS skorunun 14 ve altına inmesine etki ederek yaralanma riskini düşürdüğü yönünde sonuçland.

\section{SONUÇ}

Adolesan basketbol oyuncularında yaralanma risk oranının artmasında yaşın küçük olması, yaralanma risk oranının azalmasında ise YBT posterolateral uzanımların ve core enduransının artması etkili faktörler olarak belirlendi. Gövde fleksiyon enduransının yaralanma riski üzerine etkisi bulunmadı. Kalça abduksiyon, internal, eksternal rotasyon değerleri ve $Q$ açısı ise yaralanma risk faktörleri arasında yer almadı. Sonuç olarak adolesan sporcuların antrenman programlarını hazırlarken yaş göz önünde bulundurulmalı, core kaslarının enduransı ve denge eğitiminin antrenmanlara eklenmesinin yaralanma riskini azaltabileceği göz ardı edilmemelidir. Farklı spor branşlarında, sporcuların yaşları gruplandırılarak ve cinsiyete göre karşılaştırılarak yaralanmaya etki eden faktörlerin değerlendirilmesi yararlı olacaktır.

\section{Çıkar Çatışması ve Finansal Destek}

$\mathrm{Bu}$ çalışmada herhangi bir çıkar veya finansal çıkar çatışması yoktur.

\section{KAYNAKLAR}

1. CDC: Centers for Disease Control Injury Research Agenda: Preventing injuries in recreation, and exercise. $\quad h t t p: / / w w w . c d c . g o v / n c i p c / p u b-$ res/research_agenda/Research\%20Agenda; 2006.

2. Grimmer KA, Jones D, Williams J. Prevalence of adolescent injury from recreational exercise: an Australian perspective. $J$ Adolesc Health. 2000;27(4):266-72.

3. Abernethy L, MacAuley D. Impact of school sports injury. Br J Sports Med. 2003;37(4):354-5.

4. Chu SK, Jayabalan P, Kibler WB, Press J. The kinetic chain revisited: new concepts on throwing mechanics and injury. PM R. 2016;8(3 Suppl):S69-77.

5. Kibler WB, Wilkes T, Sciascia A. Mechanics and pathomechanics in the overhead athlete. Clin Sports Med. 2013;32(4):637-51.

6. Sciascia A, Thigpen C, Namdari S, Baldwin K. Kinetic chain abnormalities in the athletic shoulder. Sports Med Arthrosc Rev. 2012;20(1):16-21.

7. Hubscher M, Zech A, Pfeifer K, Hänsel F, Vogt L, Banzer W. Neuromuscular training for sports injury prevention: a systematic review. Med Sci Sports Exerc. 2010;42(3):413-21.

8. Kiani A, Hellquist E, Ahlqvist K, Gedeborg R, Michaëlsson K, Byberg L. Prevention of soccer-related knee injuries in teenaged girls. Arch Intern Med. 2010;170(1):43-9.

9. Knapik JJ, Bullock SH, Canada S, Toney E, Wells JD, Hoedebecke E, et al. Influence of an injury reduction program on injury and fitness outcomes among soldiers. BMJ. 2004;10(1):37-42.

10. Sadoghi P, von Keudell A, Vavken P. Effectiveness of anterior cruciate ligament injury prevention training programs. J Bone Joint Surg Am. 2012;94(9):769-76.

11. Walden $M$, Atroshi I, Magnusson $H$, Wagner $P$, Hägglund M. Prevention of acute knee injuries in adolescent female football players: cluster randomised controlled trial. BMJ. 2012;344:e3042.

12. Wedderkopp N, Kaltoft M, Lundgaard B, Rosendahl M, Froberg K. Prevention of injuries in young female players in European team handball: a prospective intervention study. Scand J Med Sci Sports. 1999;9(1):41-7.

13. DiFiori JP, Benjamin HJ, Brenner JS, Gregory A, Jayanthi N, Landry GL, et al. Overuse injuries and burnout in youth sports: a position statement from the American Medical Society for Sports Medicine. $\mathrm{Br} J$ Sports Med. 2014;48(4):287-8.

14. Luke A, Lazaro RM, Bergeron MF, Keyser L, Benjamin $\mathrm{H}$, Brenner J, et al. Sports-related injuries in youth 
athletes: is overscheduling a risk factor? Clin J Sport Med. 2011;21(4):307-14.

15. Rae K, Orchard J. The Orchard sports injury classification system (OSICS) version 10. Clin J Sport Med. 2007;17(3):201-4.

16. Smith CA, Chimera NJ, Warren M. Association of $\mathrm{Y}$ balance test reach asymmetry and injury in division I athletes. Med Sci Sports Exerc. 2014;47(1):136-41.

17. Kelleher LK, Frayne RJ, Beach TAC, Higgs JM, Johnson AM, Dickey JP. Relationships between the functional movement screen score and $\mathrm{y}$-balance test reach distances. Int J Hum Mov Sports Sci. 2017;5(3):51-6.

18. Chimera NJ, Smith CA, Warren M. Injury history, sex, and performance on the functional movement screen and Y balance test. J Athl Train. 2015;50(5):475-85.

19. Pourheydari S, Sheikhhoseini R, Hosseini SG. Correlation between the functional movement screen (FMS) test with dynamic balance and core endurance in male and female volleyball players in Kerman province. JCPR. 2018;3(2):64-9.

20. Overmoyer GV, Reiser $2^{\text {nd }} \mathrm{RF}$. Relationships between lower-extremity flexibility, asymmetries, and the $\mathrm{Y}$ balance test. J Strength Cond Res. 2015;29(5):1240-7.

21. Pefanis N, Papaharalampous X, Tsiganos G, Papadakou E, Baltopoulos $P$. The effect of $Q$ angle on ankle sprain occurrence. Foot Ankle Spec. 2009;2(1):22-6.

22. Plisky PJ, Gorman PP, Butler RJ, Kiesel KB, Underwood $\mathrm{FB}$, Elkins B. The reliability of an instrumented device for measuring components of the star excursion balance test. N Am J Sports Phys Ther. 2009;4(2):92-9.

23. Chorba RS, Chorba DJ, Bouillon LE, Overmyer CA, Landis JA. Use of a functional movement screening tool to determine injury risk in female collegiate athletes. N Am J Sports Phys Ther. 2010;5(2):47-54.

24. Hannibal III NS, Plowman SA, Looney MA, Brandenburg J. Reliability and validity of low back strength/muscular endurance field tests in adolescents. J Phys Activ Health. 2006;3(Suppl 2):7889.

25. Hibbs AE, Thompson KG, French DN, Hodgson D, Spears IR. Peak and average rectified EMG measures: Which method of data reduction should be used for assessing core training exercises? J Electromyogr Kinesiol. 2011;21(1):102-11.

26. Tse MA, McManus AM, Masters RSW. Development and validation of a core endurance intervention program: Implications for performance in college-age rowers. J Strength Cond Res. 2005;19(3):547-52.

27. Brody DM. Running Injuries. Ciba Clinical Symposia. Vol. 32, No. 4, pp 9-13; 1980.

28. Snell RS. Clinical Anatomy for Medical Students. $2^{\text {nd }}$ ed, Boston MA: Little, Brown \& Co., 1981.

29. Cook G, Burton L, Hoogenboom B. Pre-participation screening: the use of fundamental movements as an assessment of function-part 1. N Am J Sports Phys Ther. 2006;1(2):62-72.

30. Cook G, Burton L, Hoogenboom B. Pre-participation screening: The use of fundamental movements as an assessment of function-part 2. N Am J Sports Phys Ther. 2006;1(3): 132-9.

31. Butler RJ, Southers C, Gorman PP, Kiesel KB, Plisky PJ. Differences in soccer players' dynamic balance across levels of competition. J Athl Train. 2012;47(6):616-20.

32. Perry FT, Koehle MS. Normative data for the functional movement screen in middle-aged adults. $J$ Strength Cond Res. 2013;27(2):458-62.

33. Portas MD, Parkin G, Roberts J, Batterham AM. Maturational effect on Functional Movement Screen ${ }^{\text {TM }}$ score in adolescent soccer players. J Sci Med Sport. 2016;19(10):854-8.

34. Lloyd RS, Oliver JL, Radnor JM, Rhodes BC, Faigenbaum AD, Myer GD. Relationships between functional movement screen scores, maturation and physical performance in young soccer players. J Sports Sci. 2015;33(1):11-9. 